\title{
Optical Arithmetic Operation Using Optical Demultiplexer
}

\section{Dilip Kumar Gayen}

Department of Computer Science \& Engineering, College of Engineering \& Management, Kolaghat, India

Email: dilipgayen@yahoo.com

How to cite this paper: Gayen, D.K. (2016)

Optical Arithmetic Operation Using Optical

Demultiplexer. Circuits and Systems, 7, 3485-3493.

http://dx.doi.org/10.4236/cs.2016.711296

Received: May 11, 2016

Accepted: May 21, 2016

Published: September 6, 2016

Copyright $\odot 2016$ by author and Scientific Research Publishing Inc. This work is licensed under the Creative Commons Attribution International License (CC BY 4.0).

http://creativecommons.org/licenses/by/4.0/

\begin{abstract}
Using Terahertz Optical Asymmetric Demultiplexer (TOAD) based switch we have designed all-optical parallel half adder and full adder. The approach to design this all-optical arithmetic circuit not only enhances the computational speed but also is capable of synthesizing light as input to produce desire output. The main advantage of parallel circuit is synchronization of input which is not required. All the circuits are designed theoretically and verified through numerical simulations.
\end{abstract}

\section{Keywords}

Terahertz Optical Asymmetric Demultiplexer, Semiconductor Optical Amplifier, Half Adder, Full Adder, Optical Logic

\section{Introduction}

Nowadays high speed all-optical logic gates are crucial devices in optical networks because they execute essential signal processing function such as switching regeneration and header recognition processing in photonic switching nodes. A revolution has been brought about in all-optical information processing system with the help of the discovery of ultra high speed all-optical switches based on cross phase modulation (XPM) [1]-[4]. Among different optical switches, the terahertz optical asymmetric demultiplexer (TOAD)/semiconductor optical amplifier (SOA)-assisted Sagnac gate effectively combines fast switching time, high repetition rate, and low power consumption [5][10]. In this paper we propose and describe the all-optical parallel half adder and full adder using TOAD based all-optical switches. We have utilized both the transmitted and reflected port of the device. 


\section{Operation of TOAD Based Switch}

The basic design of TOAD based switch is shown in Figure 1 [11] [12]. Here a nonlinear element (NLE) is placed asymmetrically in a loop. The coon NLE is semiconductor optical amplifier (SOA). In this paper, we have tried to use the output from both the transmitting and reflecting mode of the device. The output power at upper and lower can be expressed as [13]-[15]

$$
\begin{gathered}
P_{\text {Upper }}(t)=\frac{P_{\text {in }}(t)}{4} \cdot\left\{G_{c w}(t)+G_{c c w}(t)-2 \sqrt{G_{c w}(t) \cdot G_{c c w}(t)} \cdot \cos (\Delta \varphi)\right\} \\
P_{\text {Lower }}(t)=\frac{P_{\text {in }}(t)}{4} \cdot\left\{G_{c w}(t)+G_{c c w}(t)+2 \sqrt{G_{c w}\left((t) \cdot G_{c c w}(t)\right.} \cdot \cos (\Delta \varphi)\right\}
\end{gathered}
$$

where, $G_{c w}(t), G_{c c w}(t)$ is the power gain. The time-dependent phase difference between clockwise (CW) and counter clockwise (CCW) pulses [13] is $\Delta \varphi=\alpha / 2$. $\ln \left(G_{c w}(t) / G_{c c w}(t)\right)$ with $\alpha$ being the line-width enhancement factor.

In the absence of a control signal, data signal (incoming signal) enters the fiber loop, pass through the SOA at different times as they counter-propagate around the loop, and experience the same unsaturated small amplifier gain $G_{s s}$ and recombine at the input coupler i.e. $G_{c c w} \approx G_{c w}$. Then, $\Delta \varphi \approx 0$ and expression for $P_{U p p e r}(t) \approx 0$ and $P_{\text {Lower }}(t)=P_{\text {in }}(t) \cdot G_{s s}$. It shows that data is reflected back toward the source. When a control pulse is injected into the loop, it saturates the SOA and changes its index of refraction. The gain of SOA decreases rapidly [13]-[15]. As a result, the two counter-propagation data signal will experience a differential gain saturation profiles i.e. $G_{c c w} \neq G_{c w}$. Therefore they recombine at the input coupler, and then $\Delta \varphi \approx-\pi$ the data will exit from the upper port i.e. $P_{U p p e r}(t) \neq 0$ and $P_{\text {Lower }}(t) \approx 0$, the corresponding

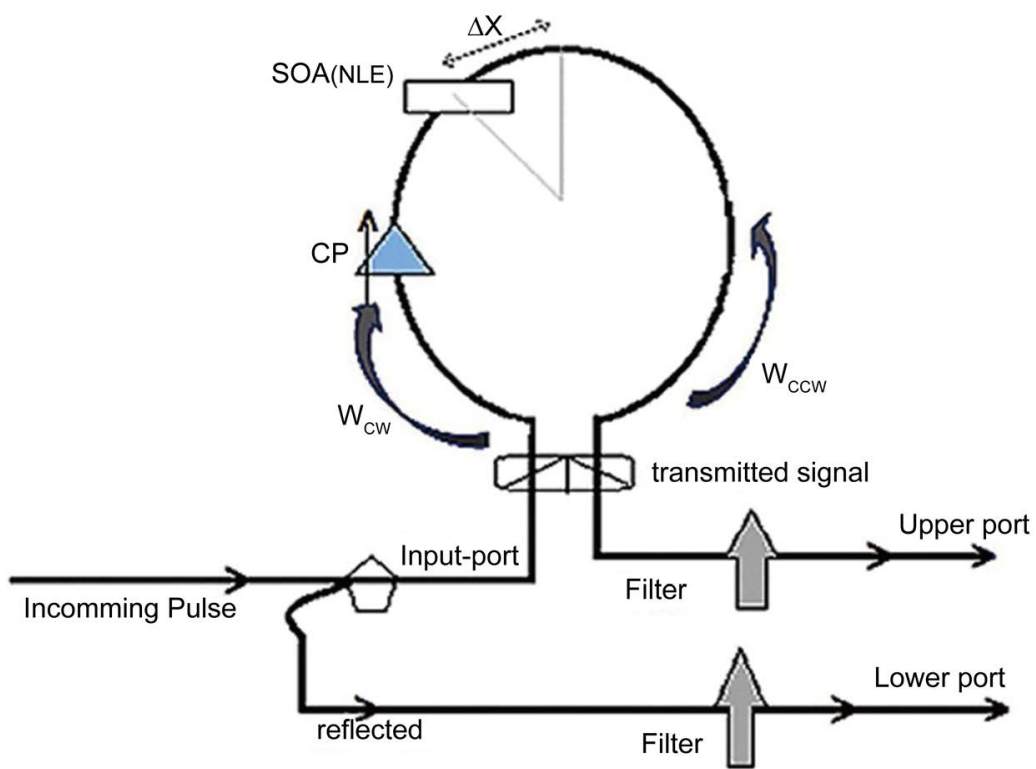

Figure 1. A TOAD based optical switch with single control pulse (CP), where SOA: Semiconductor optical amplifier, CW: Clockwise pulse, CCW: Counterclockwise pulse and $\Delta \mathrm{x}$ : asymmetric distance. 
values can be obtained from the Equation (2). The energy of the control pulse is ten times greater than that of the incoming pulse. A filter may be used at the output of TOAD based switch to reject the control and pass the incoming pulse. The schematic diagram of TOAD based switch is shown in Figure 2.

\section{All-Optical Parallel Half Adder}

A half adder circuit adds two one-bit binary numbers (A and B) and gives the output of two one-bit binary numbers, a sum (S) and a carry (Cout). The operational principle of all-optical parallel half adder is shown in Figure 3. To implement this circuit, we use TOAD-based switches namely, T1 to T4. There are 4 different input combinations for implementing double input binary logic. Depending on the state of input variables (A

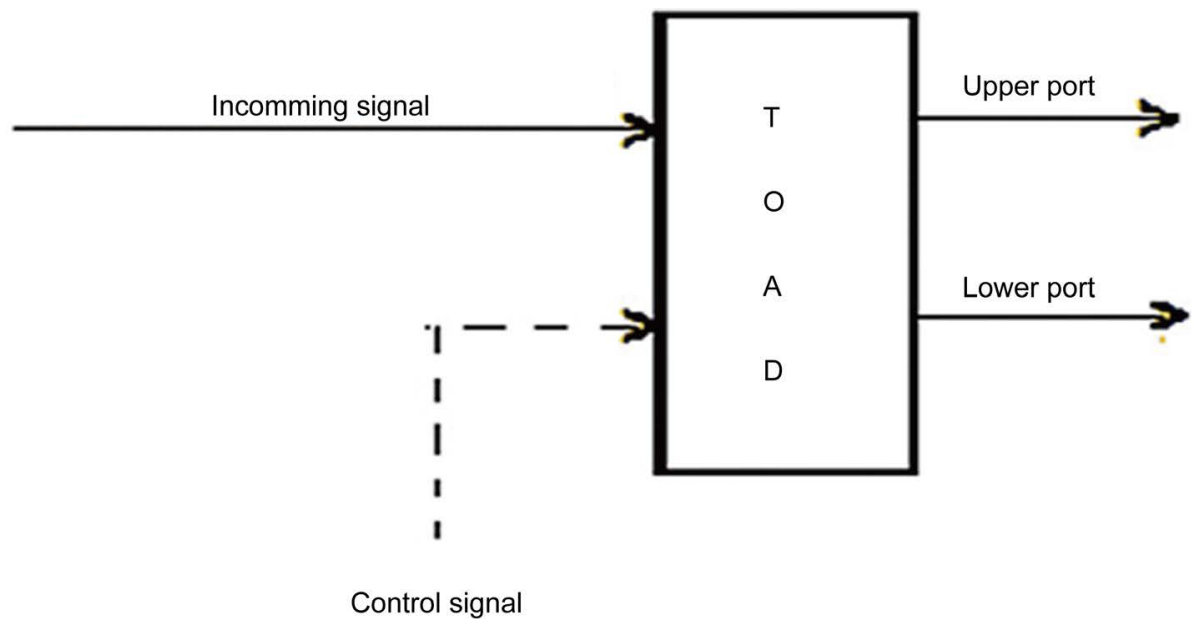

Figure 2. The schematic diagram of TOAD based switch.

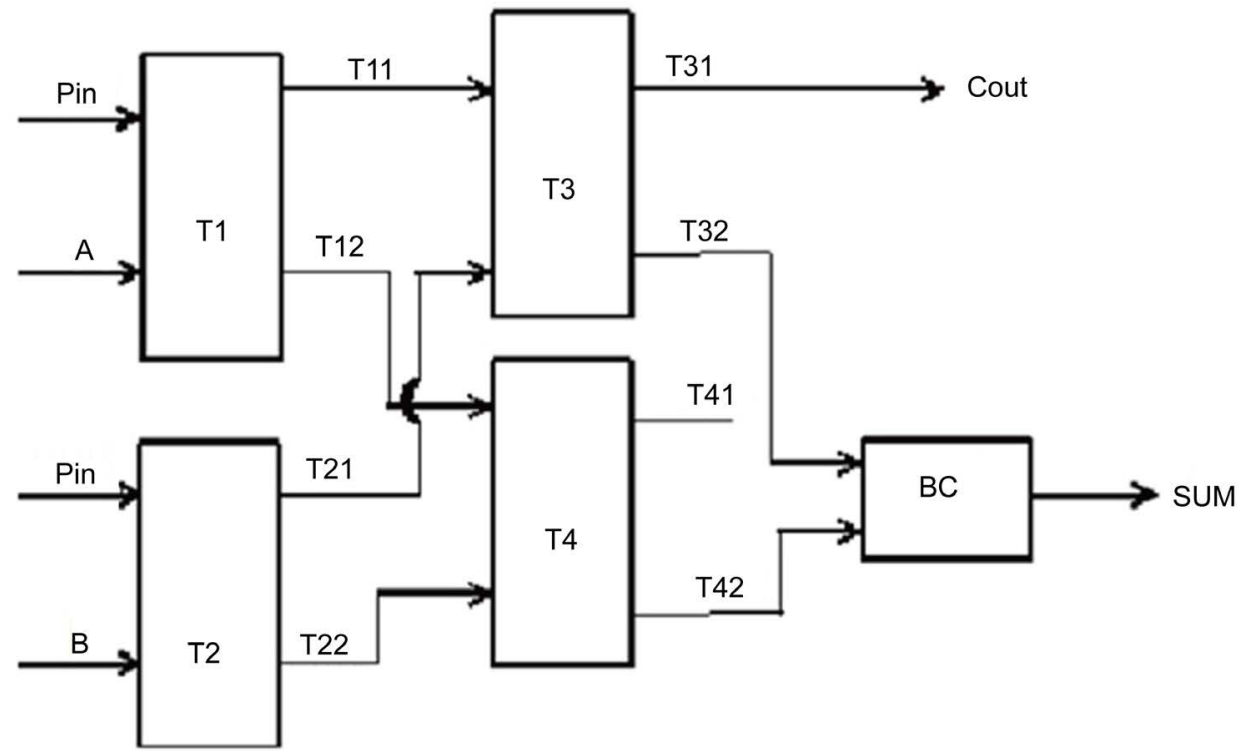

Figure 3. All-optical parallel half adder, A, B: Inputs, T1 - T4: TOAD based switches, BC: Beam combiner and Sum, Cout: Outputs. 
and B) [These are the light signals]. The output of the corresponding circuit is obtained from Beam Combiner (BC) as Sum and T31 as Cout. Four Cases are described below in detail.

CASE 1: When $A=0$ and $B=0$. Light from the Pin is incident on switch T1 and T2. As the control signal A, B is absent light emerges through the lower channel of T1, T2 as $\mathrm{T} 12=1, \mathrm{~T} 22=1$ respectively. $\mathrm{T} 21=0$ and $\mathrm{T} 22=1$ falls on lower channel of T3 and $\mathrm{T} 4$ respectively and $\mathrm{T} 11=0$ and $\mathrm{T} 12=1$ falls on upper channel of T3 and T4 respectively, produces output as $\mathrm{T} 31=0, \mathrm{~T} 32=0, \mathrm{~T} 42=0$. Now $\mathrm{T} 32$ and $\mathrm{T} 42$ feed to $\mathrm{BC}$ to get output as Sum $=0$. Upper output channel of switch T3 i.e., T31 produces Cout $=0$.

CASE 2: When $\mathrm{A}=0$ and $\mathrm{B}=1$. Light emerges out from $\mathrm{T} 42$ only i.e., from lower output channel of switch T4. So, T31 and T32 become 0 . Hence Sum $=1(\mathrm{~T} 42+\mathrm{T} 32)$ and Cout $=0$ (T31).

CASE 3: When $\mathrm{A}=1$ and $\mathrm{B}=0$. Light emerges out from $\mathrm{T} 32$ only i.e., from lower output channel of switch T3. So, T31 and T42 become 0 . Hence Sum $=1(\mathrm{~T} 42+\mathrm{T} 32)$ and Cout $=0(\mathrm{~T} 31)$.

CASE 4: When $\mathrm{A}=1$ and $\mathrm{B}=1$. Light emerges out from T31 only i.e., from upper output channel of switch T3. So, T32 and T42 become 0 . Hence Sum $=0(\mathrm{~T} 42+\mathrm{T} 32)$ and Cout $=1(\mathrm{~T} 31)$.

Hence, Sum $=(A \oplus B)$ and Cout $=\mathrm{AB}$. In this way addition of any two bit number can be done with this circuit.

\section{All-Optical Parallel Full Adder}

A full adder circuit adds three one-bit binary numbers (A, B, and C) and gives the output of two one-bit binary numbers, a sum (S) and a carry (Cout). The operational principle of all-optical parallel full-adder is explained in Figure 4. To implement this circuit, we use TOAD-based switches namely, T1 to T9. There are 8 different input combinations for implementing triple input binary logic.

Depending on the state of input variables (A, B, and $\mathrm{C}$ ) output of the corresponding circuit is obtained from BC2 for Carry Out and BC3 for Sum, respectively. The advantage of this circuit is no synchronization among the inputs are required which was compulsory for other previously designed full adders, it is a fully parallel circuit. Eight Cases are described below in detail.

CASE 1: When $\mathrm{A}=0, \mathrm{~B}=0$ and $\mathrm{C}=0$. Light from the Pin is incident on switch $\mathrm{T} 1$, T2, T3. As the control signal A, B, C is absent light emerges through the lower channel of $\mathrm{T} 1, \mathrm{~T} 2$ and $\mathrm{T} 3$ as $\mathrm{T} 12=1, \mathrm{~T} 22=1$ and $\mathrm{T} 32=1$ respectively. $\mathrm{T} 21=0, \mathrm{~T} 22=1$ and $\mathrm{T} 31=0$ falls on lower channel of $\mathrm{T} 4, \mathrm{~T} 5$ and $\mathrm{T} 8$ respectively and $\mathrm{T} 11=0, \mathrm{~T} 12=1$ and Pin falls on upper channel of T4, T5 and T8 respectively, produces output as $\mathrm{T} 41=0$, $\mathrm{T} 42=0, \mathrm{~T} 52=0$ and $\mathrm{T} 81=0$. Now $\mathrm{T} 42$ and $\mathrm{T} 52$ feed to $\mathrm{BC} 1$ to get output as $\mathrm{X}=0$. Again, $\mathrm{X}$ is applied on upper and lower channel of switch T6 and T7 as input respectively, also T41 is applied on lower channel of T9 and T81 is applied on lower and upper channel of switch T6 and T7 as input respectively and Pin is applied on upper channel of T9 Hence, T91 $=0$. Switch T6 produces output as X2 $=0$ from its upper 


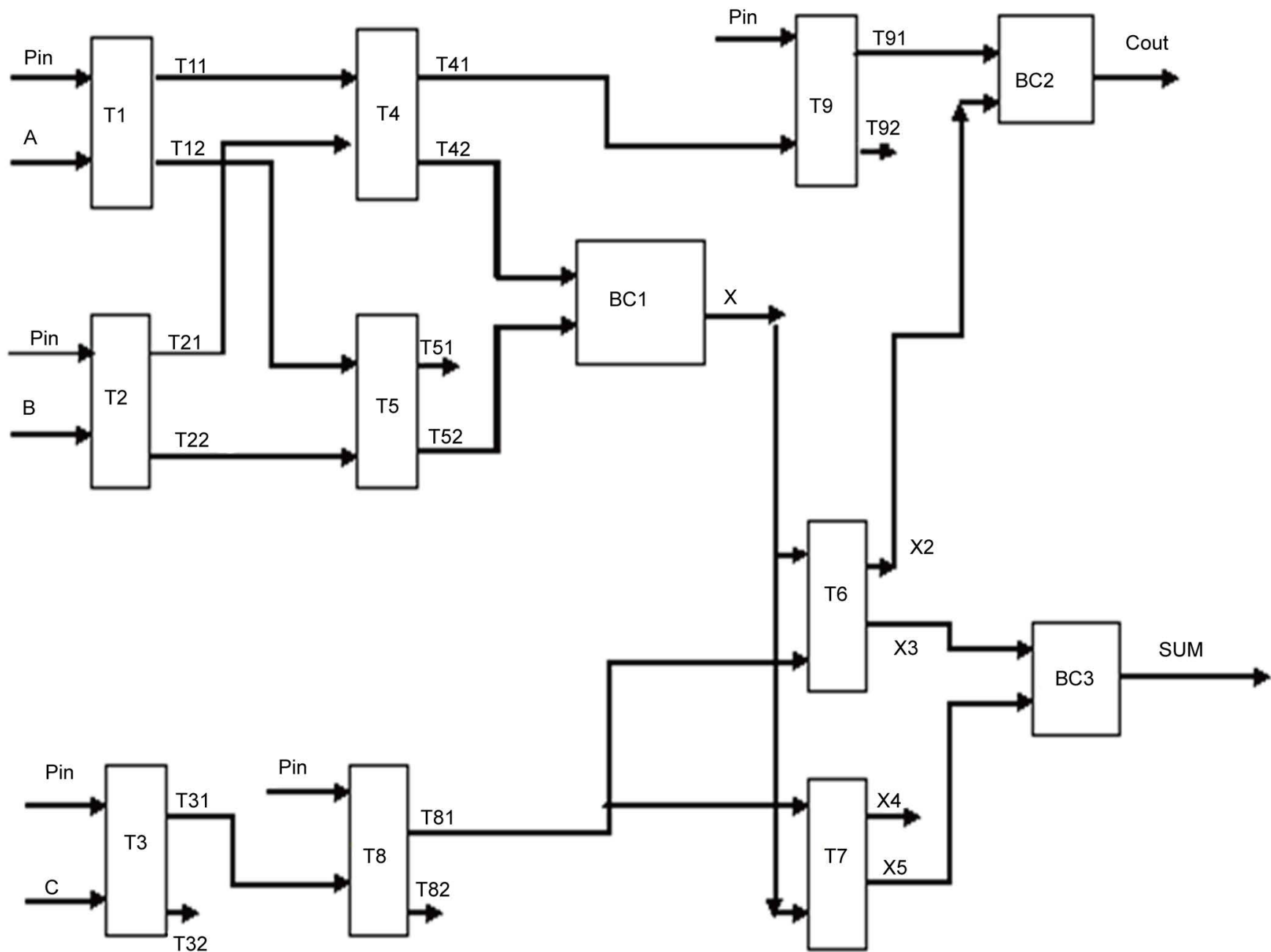

Figure 4. All-optical parallel full adder, A, B, C: Inputs, T1 - T9: TOAD based switches, BC1 - BC3: Beam combiners and Sum, Cout: Outputs.

channel and $\mathrm{X} 3=0$ from its lower channel. Switch T7 produces output $\mathrm{X} 4=0$ from its upper channel and X5 $=0$ from its lower channel. Now X3 and X5 is combined using $\mathrm{BC} 3$ to produce output Sum $=0 . \mathrm{X} 2$ and $\mathrm{T} 91$ is combined using BC2 to produce Cout $=$ 0 .

CASE 2: When $\mathrm{A}=0, \mathrm{~B}=0$ and $\mathrm{C}=1$. Light emerges out from $\mathrm{X} 5$ only i.e., from lower output channel of switch T7. So, T91, X3 and X2 becomes 0 . Hence Sum $=1$ (X3 $+\mathrm{X} 5)$ and Cout $=0(\mathrm{~T} 91+\mathrm{X} 2)$.

CASE 3: When $\mathrm{A}=0, \mathrm{~B}=1$ and $\mathrm{C}=0$. Light emerges out from $\mathrm{X} 3$ only i.e., from lower output channel of switch T6. So, T91, X2 and X5 becomes 0. Hence Sum $=1$ (X3 $+\mathrm{X} 5)$ and Cout $=0(\mathrm{~T} 91+\mathrm{X} 2)$.

CASE 4: When $\mathrm{A}=0, \mathrm{~B}=1$ and $\mathrm{C}=1$. Light emerges out from $\mathrm{X} 2$ only i.e., from upper output channel of switch T6. So, T91, X3 and X5 becomes 0 . Hence Sum $=0$ (X3 $+\mathrm{X} 5)$ and Cout $=1(\mathrm{~T} 91+\mathrm{X} 2)$.

CASE 5: When $\mathrm{A}=1, \mathrm{~B}=0$ and $\mathrm{C}=0$. Light emerges out from $\mathrm{X} 3$ only i.e., from 
lower output channel of switch T6. So, T91, X2 and X5 becomes 0. Hence Sum = 1 (X3 $+\mathrm{X} 5)$ and Cout $=0(\mathrm{~T} 91+\mathrm{X} 2)$.

CASE 6: When $\mathrm{A}=1, \mathrm{~B}=0$ and $\mathrm{C}=1$. Light emerges out from $\mathrm{X} 2$ only i.e., from upper output channel of switch T6. So, T91, X3 and X5 becomes 0 . Hence Sum $=0$ (X3 $+\mathrm{X} 5)$ and Cout $=1(\mathrm{~T} 91+\mathrm{X} 2)$.

CASE 7: When $\mathrm{A}=1, \mathrm{~B}=1$ and $\mathrm{C}=0$. Light emerges out from $\mathrm{T} 91$ only i.e., from upper output channel of switch T9. So, X2, X3 and X5 becomes 0 . Hence Sum $=0$ (X3 + $\mathrm{X} 5)$ and Cout $=1(\mathrm{~T} 91+\mathrm{X} 2)$.

CASE 8: When $\mathrm{A}=1, \mathrm{~B}=1$ and $\mathrm{C}=1$. Light emerges out from $\mathrm{X} 5$ and $\mathrm{T} 91$ i.e., from lower output channel of switch T7 and upper output channel of switch T9 respectively. So, X3 and X2 becomes 0 . Hence Sum $=1(\mathrm{X} 3+\mathrm{X} 5)$ and Cout $=1(\mathrm{~T} 91+\mathrm{X} 2)$.

In this way addition of any three bit number can be done with this circuit.

\section{Simulated Results}

The parameters used in this simulation are taken from the literature survey of different research papers [10] [13]-[15]. The values of different parameters as : unsaturated amplifier gain of the SOA $\left(\mathrm{G}_{\mathrm{ss}}\right)=30 \mathrm{~dB}$, gain recovery time of SOA $\left(\tau_{\mathrm{e}}\right)=90 \mathrm{ps}$, saturation energy of the SOA $\left(\mathrm{E}_{\mathrm{sat}}\right)=700 \mathrm{fJ}$, eccentricity of the loop $\left(\mathrm{T}_{\text {asym }}\right)=30 \mathrm{ps}$, line-width enhancement factor $(\alpha)=6$, full width at half maximum of control pulse $(\sigma)=6 \mathrm{ps}$, bit period $\left(\mathrm{T}_{\mathrm{c}}\right)=100 \mathrm{ps}$, and a control pulse energy $\left(\mathrm{E}_{\mathrm{cp}}\right)=70 \mathrm{fJ}$ so that the operational conditions are satisfied. The simulated input and output waveforms of half adder are shown in Figure 5 and Figure 6, respectively. The simulated input and output waveforms of full adder are shown in Figure 7 and Figure 8, respectively.

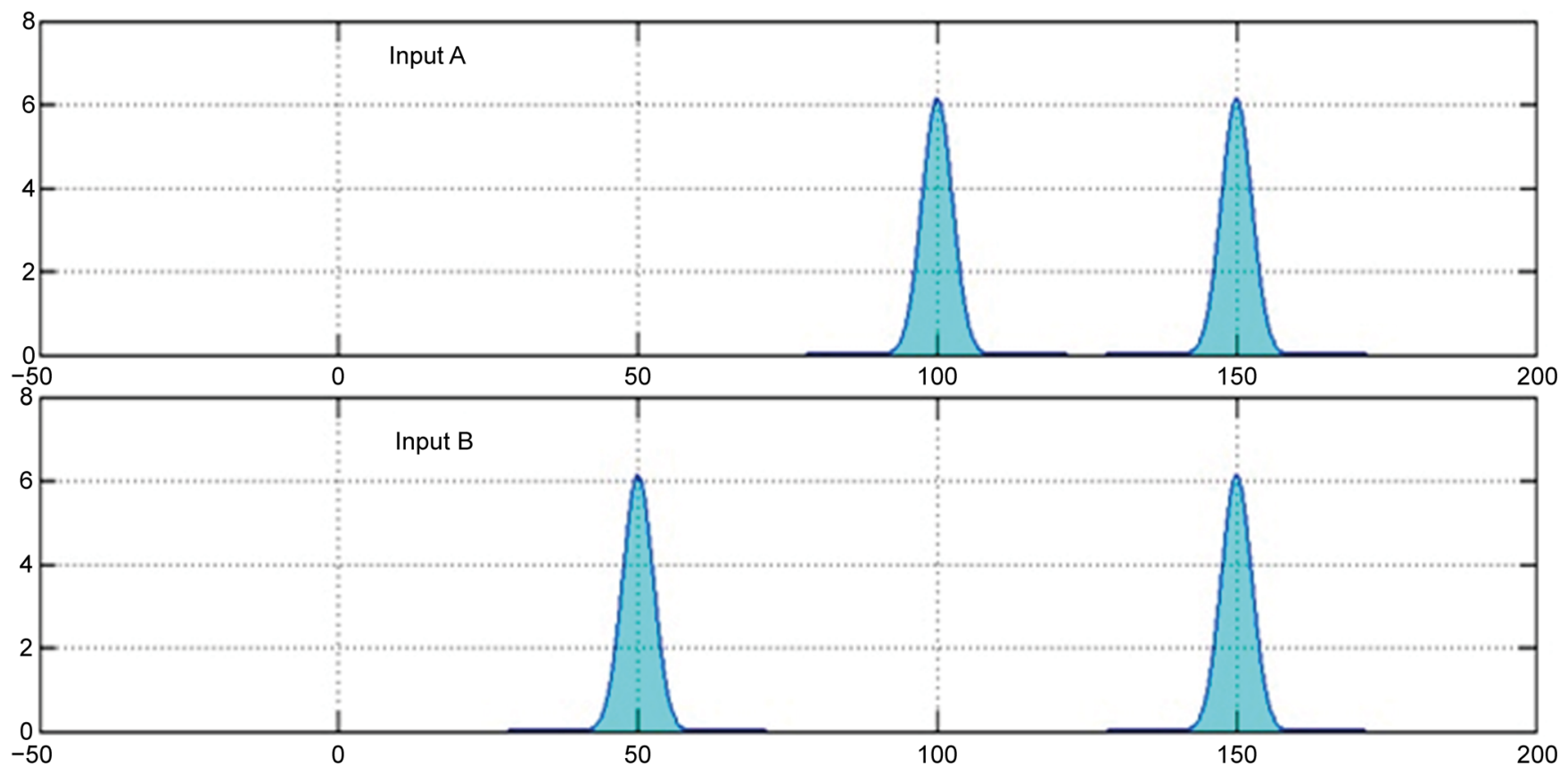

Figure 5. Simulated input waveforms of parallel half adder, where power (Watt) is along the y-axis whereas time (ps) is along the $\mathrm{x}$-axis. 


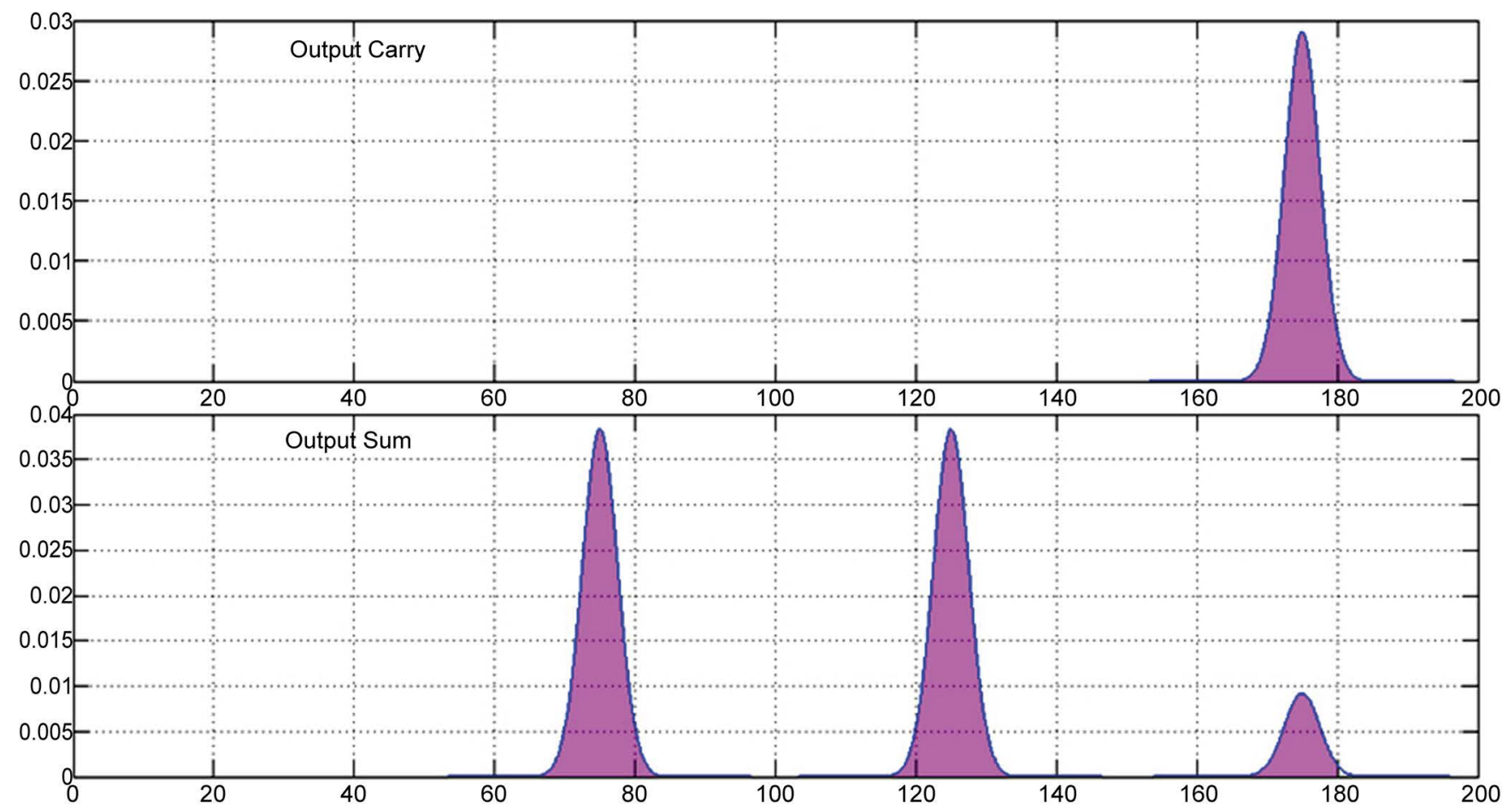

Figure 6. Simulated output waveforms of parallel half adder, where power (Watt) is along the y-axis whereas time (ps) is along the $\mathrm{x}$-axis.

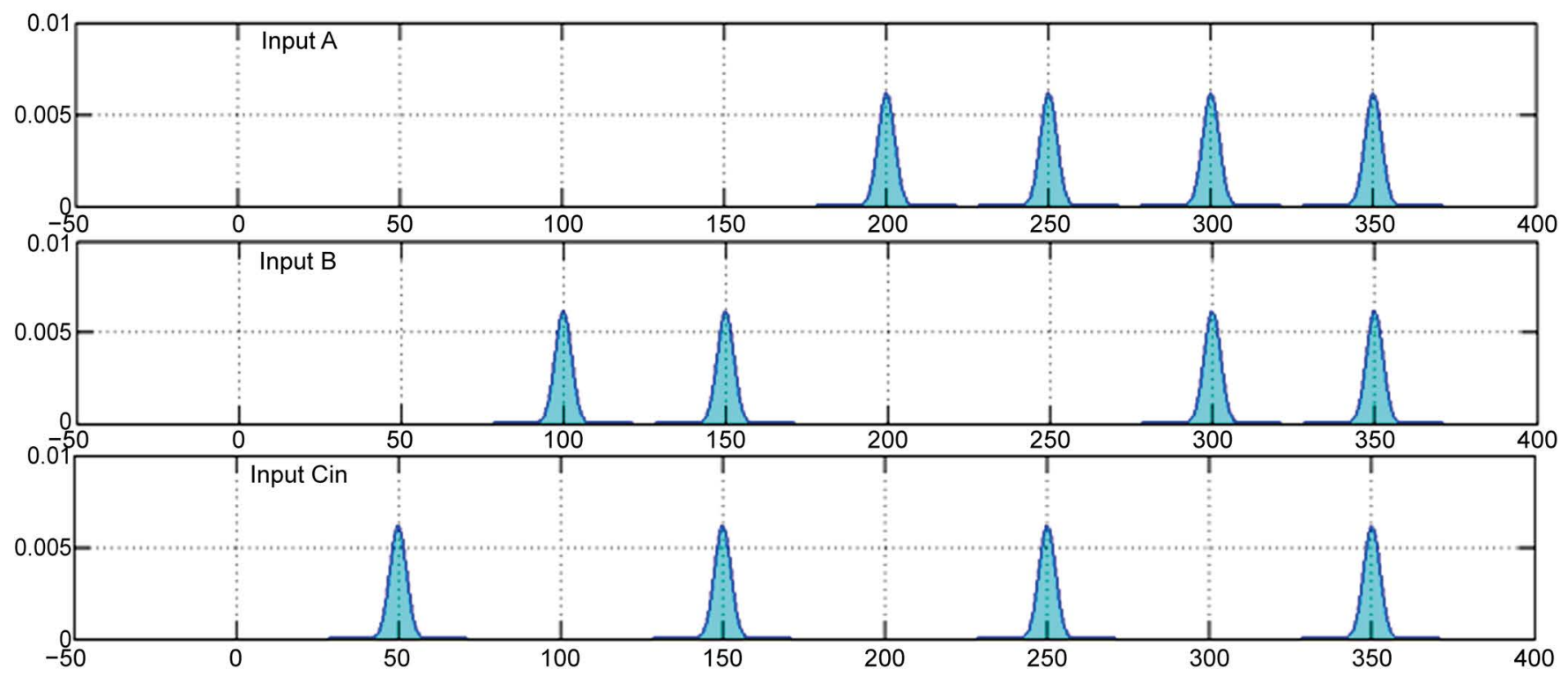

Figure 7. Simulated input waveforms of parallel full adder, where power (Watt) is along the $y$-axis whereas time (ps) is along the $\mathrm{x}$-axis.

\section{Conclusion}

In this paper, we have reported parallel all-optical half adder and full adder. Here, in this proposed scheme, the significant advantage is that the proposed circuit can perform addition operations, which are all-optical in nature. This theoretical model has been verified through numerical simulation. 


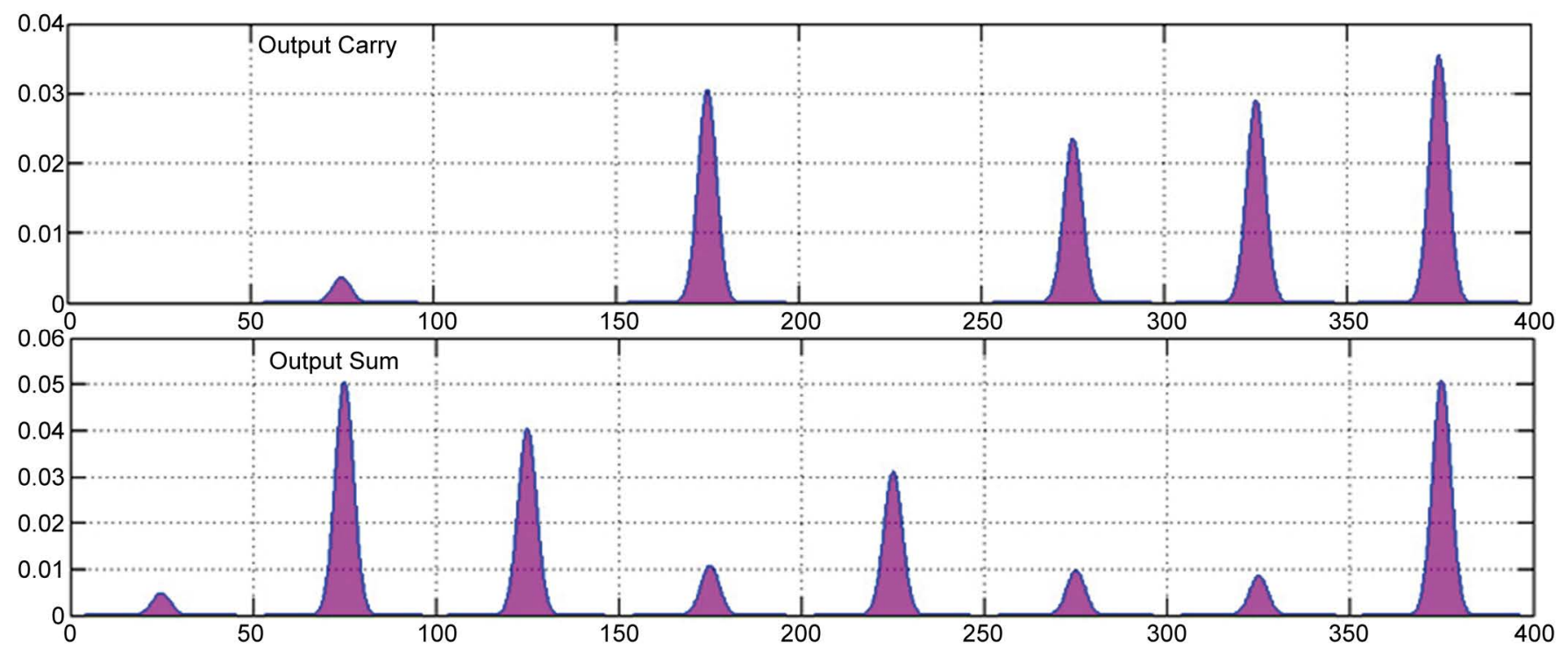

Figure 8. Simulated output waveforms of parallel full adder, where power (Watt) is along the $\mathrm{y}$-axis whereas time (ps) is along the $\mathrm{x}$-axis.

\section{Acknowledgements}

The authors are grateful to Technical Education Quality Improvement Programme (TEQIP) phase II by National Project Implementation Unit (Approval No.-CEMK/ TEQIP-II/R\&D/Project/15-16/03) for providing the grant for this work.

\section{References}

[1] Cotter, D., Manning, R.J., Blow, K.J., Ellis, A.D., Kelly, A.E., Nesset, D., Phillips, I.D., Poustie, A.J. and Rogers, D.C. (1999) Nonlinear Optics for High-Speed Digital Information Processing. Science, 286, 1523-1528. http://dx.doi.org/10.1126/science.286.5444.1523

[2] Suzuki, M. and Uenohara, H. (2009) Investigation of All-Optical Error Detection Circuit Using SOA-MZI Based XOR Gates at 10 Gbit/s. Electronics Letters, 45, 224. http://dx.doi.org/10.1049/el:20093461

[3] Minh, H.L., Ghassemlooy, Z. and Ng, W.P. (2008) Characterization and Performance Analysis of a TOAD Switch Employing a Dual Control Pulse Scheme in High Speed OTDM Demultiplexer. IEEE Communications Letters, 12, 316-318. http://dx.doi.org/10.1109/LCOMM.2008.061299

[4] Li, G. (2009) Recent Advances in Coherent Optical Communication. Advances in Optics and Photonics, 1, 279-307. http://dx.doi.org/10.1364/AOP.1.000279

[5] Bhattacharyya, A., Gayen, D.K. and Chattopadhyay, T. (2012) 4-Bit All-Optical Binary to Two's Complement Converter. Proceedings of International Conference on Communications, Devices and Intelligent Systems, 496-499. http://dx.doi.org/10.1109/codis.2012.6422247

[6] Bhattacharyya, A., Gayen, D.K. and Chattopadhyay, T. (2013) Alternative All-Optical Circuit of Binary to BCD Converter Using Terahertz Asymmetric Demultiplexer Based Interferometric Switch. Proceedings of $1^{\text {st }}$ International Conference on Computation and Communication Advancement (IC3A-2013), India, 11-12 January 2013, 1-4.

[7] Gayen, D.K. and Roy, J.N. (2008) All-Optical Arithmetic Unit with the Help of Terahertz Optical Asymmetric Demultiplexer (TOAD) Based Tree Architecture. Applied Optics, 47, 
933-943. http://dx.doi.org/10.1364/AO.47.000933

[8] Melo, A.M., Lima, J.L.S., de Oliveira, R.S. and Sombra, A.S.B. (2002) Photonic Time Division Multiplexing (OTDM) Using Ultra-Short Picosecond Pulses in a Terahertz Optical Asymmetric Demultiplexer (TOAD). Optics Communications, 205, 299-312. http://dx.doi.org/10.1016/S0030-4018(02)01377-9

[9] Wang, B., Baby, V., Tong, W., Xu, L., Friedman, M., Runser, R., Glesk, I. and Prucnal, P. (2002) A Novel Fast Optical Switch Based on Two Cascaded Terahertz Optical Asymmetric Demultiplexers (TOAD). Optics Express, 10, 15-23. http://dx.doi.org/10.1364/OE.10.000015

[10] Zoiros, K.E., Vardakas, J., Houbavlis, T. and Moyssidis, M. (2005) Investigation of SOAAssisted Sagnac Recirculating Shift Register Switching Characteristics. International Journal for Light and Electron Optics, 116, 527-541. http://dx.doi.org/10.1364/OE.10.000015

[11] Sokoloff, J.P., Prucnal, P.R., Glesk, I. and Kane, M. (1993) A Terahertz Optical Asymmetric Demultiplexer (TOAD). IEEE Photonic Technology Letters, 5, 787-789.

http://dx.doi.org/10.1109/68.229807

[12] Sokoloff, J.P., Glesk, I., Prucnal, P.R. and Boneck, R.K. (1994) Performance of a 50 Gbit/s Optical Time Domain Multiplexed System Using a Terahertz Optical Asymmetric Demultiplexer. IEEE Photonics Technology Letters, 6, 98-100. http://dx.doi.org/10.1109/68.265902

[13] Eiselt, M., Pieper, W. and Weber, H.G. (1995) SLALOM: Semiconductor Laser Amplifier in a Loop Mirror. Journal of Lightwave Technology, 13, 2099-2112. http://dx.doi.org/10.1109/50.469721

[14] Zoiros, K.E., Vardakas, J., Houbavlis, T. and Moyssidis, M. (2005) Investigation of SOAAssisted Sagnac Recirculating Shift Register Switching Characteristics. International Journal for Light and Electron Optics, 116, 527-541.

http://dx.doi.org/10.1016/j.ijleo.2005.03.005

[15] Gayen, D.K., Chattopadhyay, T., Das, M.K., Roy, J.N. and Pal, R.K. (2011) All-Optical Binary to Gray Code and Gray to Binary Code Conversion Scheme with the Help of Semiconductor Optical Amplifier-Assisted Sagnac Switch. IET Circuits, Devices \& Systems, 5, 123-131. http://dx.doi.org/10.1049/iet-cds.2010.0069

Submit or recommend next manuscript to SCIRP and we will provide best service for you:

Accepting pre-submission inquiries through Email, Facebook, LinkedIn, Twitter, etc.

A wide selection of journals (inclusive of 9 subjects, more than 200 journals)

Providing 24-hour high-quality service

User-friendly online submission system

Fair and swift peer-review system

Efficient typesetting and proofreading procedure

Display of the result of downloads and visits, as well as the number of cited articles

Maximum dissemination of your research work

Submit your manuscript at: http://papersubmission.scirp.org/ 